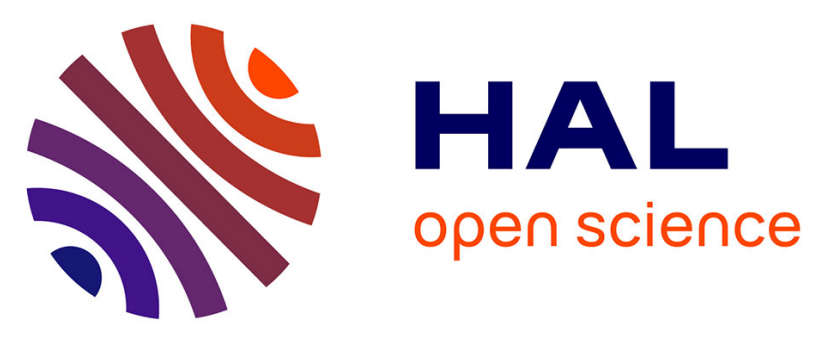

\title{
Potential impacts of extreme weather events in main maize (Zea mays L.) producing areas of South Africa under rainfed conditions
}

Robert Mangani, Eyob H Tesfamariam, Christien J Engelbrecht, Gianni Bellocchi, Abubeker Hassen, Tshepiso Mangani

\section{To cite this version:}

Robert Mangani, Eyob H Tesfamariam, Christien J Engelbrecht, Gianni Bellocchi, Abubeker Hassen, et al.. Potential impacts of extreme weather events in main maize (Zea mays L.) producing areas of South Africa under rainfed conditions. Regional Environmental Change, 2019, 19 (5), pp.1441-1452. 10.1007/s10113-019-01486-8 . hal-03113867

\section{HAL Id: hal-03113867 https://hal.inrae.fr/hal-03113867}

Submitted on 18 Jan 2021

HAL is a multi-disciplinary open access archive for the deposit and dissemination of scientific research documents, whether they are published or not. The documents may come from teaching and research institutions in France or abroad, or from public or private research centers.
L'archive ouverte pluridisciplinaire HAL, est destinée au dépôt et à la diffusion de documents scientifiques de niveau recherche, publiés ou non, émanant des établissements d'enseignement et de recherche français ou étrangers, des laboratoires publics ou privés. 


\title{
Potential impacts of extreme weather events in main maize (Zea mays L.) producing areas of South Africa under rainfed conditions
}

\author{
Robert Mangani ${ }^{1}$ (D) Eyob H. Tesfamariam ${ }^{1}$. Christien J. Engelbrecht ${ }^{2,3} \cdot$ Gianni Bellocchi $^{4} \cdot$ Abubeker Hassen $^{5}$. \\ Tshepiso Mangani $^{2}$
}

Received: 26 November 2018 / Accepted: 12 March 2019 / Published online: 30 March 2019

(C) Springer-Verlag GmbH Germany, part of Springer Nature 2019, corrected publication 2019

\begin{abstract}
An important topic of global concern is the likely reduction of maize production in response to climate change in association with increased frequency and intensity of extreme weather events, which threatens food security. We quantified the response of maize yield to projected climate changes in three main maize growing areas of South Africa (Bloemfontein, Lichtenburg and Nelspruit) using two crop modelling solutions: existing (EMS) and modified (MMS) CropSyst. The MMS considers explicitly the impact of extreme heat and drought. Both solutions were run with climate data generated from two radiative forcing scenarios using six general circulation models and three time horizons representing baseline (1990-2020), near future (2021-2050) and far future (2051-2080) time periods. Reduced yields were projected with both modelling solutions especially under far future time period. Simulated maize yield using EMS with high radiative forcing for far future decreased (compared with the simulated baseline for EMS) by 30\%, 25.9\% and $18.3 \%$ at Bloemfontein, Lichtenburg and Nelspruit, respectively. Simulated grain yield with MMS showed reductions of 27.6\%, $24.3 \%$ and $18.7 \%$, respectively (compared with the simulated baseline for MMS). Grain yield differences between the EMS and MMS ranged between 9 and $21 \%$. This difference showed an increasing trend as time progressed from the baseline to the far future and varied across locations. Accounting explicitly for the impact of extreme weather events (MMS) resulted in lower simulated yields compared with the model without (EMS). Findings from this study warrant the need for location-specific model simulation using MMS-type models to improve crop yield predictions under climate change for better food security planning and policy formulation.
\end{abstract}

Keywords Climate change scenario $\cdot$ Food security $\cdot$ Maize production $\cdot$ Modified CropSyst $\cdot$ Radiative forcing

\section{Editor: Wolfgang Cramer}

Electronic supplementary material The online version of this article (https://doi.org/10.1007/s10113-019-01486-8) contains supplementary material, which is available to authorized users.

Robert Mangani manganirob@gmail.com

Eyob H. Tesfamariam eyob.tesfamariam@up.ac.za

1 Department of Plant and Soil Science, University of Pretoria, Private Bag x20, Hatfield, Pretoria 0028, South Africa

2 Institute for Soil, Climate and Water, Agricultural Research Council, Pretoria, South Africa

3 Department of Geography, Geoinformatics and Meteorology, University of Pretoria, Private Bag x20, Hatfield, Pretoria 0028, South Africa

4 UREP, INRA 63000, Clermont-Ferrand, France

5 Department of Animal and Wildlife Sciences, Faculty of Natural- and Agricultural Sciences, University of Pretoria, Private Bag x20, Hatfield 0028, Pretoria 0002, South Africa

\section{Introduction}

An important topic of global concern is the probable reduction in maize (Zea maize L.) production in response to climate change, in association with extreme weather events (Abraha and Savage 2006). Immense progress has been made in dispensing climate-related data and agricultural yield projections (Abraha and Savage 2006). However, uncertainties persist around the reliability of the data used for climate projections, the inability to mimic experimentally future ecosystems or the atmospheric conditions that will prevail in the future and, lastly, the inability of existing crop models to fully account for the impacts of climate change (Abraha and Savage 2006; Zinyengere et al. 2014). This has been exacerbated by the projected increase in the intensity and frequency of extreme weather events under climate change (Mangani et al. 2018). In fact, most crop models have shown limits in taking into account the impacts of extreme weather 
events (van der Velde et al. 2012; Zinyengere et al. 2014). For this study, we have used a modified version of the crop model CropSyst (after Stöckle et al. 1994; Stöckle et al. 1997), which includes algorithms explicitly taking into account the impacts of extreme weather events on crop production, and can thus be used to simulate maize production. The model has been calibrated and validated for maize in South Africa (Mangani et al. 2018).

A few modelling studies have been performed in South Africa to try to understand and quantify the impacts of projected climate change on maize production (Abraha and Savage 2006; Walker and Schulze 2006; Walker and Schulze 2008). These studies used CERES-maize and CropSyst crop models to predict maize production under climate change without taking into account explicitly the impact of extreme weather events on crop growth and development. Mangani et al. (2018) reported that crop models, which do not take extreme weather events into account, tend to overestimate crop yields when extreme weather events prevail in projected future climate change. This has some implications on food security planning at country level. Policy making not accounting properly for the impacts of extreme events could likely underestimate the expected food supply, with the risk to leave a sizeable number of people food insecure.

Maize is the most important grain crop in South Africa, being both the major feed grain and the staple food of the majority of the South African population (DAFF 2016). At global scale, South Africa is ranked ninth and in SubSaharan Africa second in terms of maize production (Estes et al. 2013). In this country, approximately $60 \%$ of the agricultural land comprises maize cultivation, maize contributing nearly $70 \%$ of the grain production (Akpalu et al. 2009). South Africa produces on average nearly 10.2 million tons a year, and approximately 8 million tons of this annual production is used locally as food and fodder (FAO 2012). Over the past five growing seasons, maize has been the largest contributor to the gross value of field crops (48\%), followed by sugar cane $(13.2 \%)$, wheat $(9.7 \%)$ and both soybean and hay (7.4\%) (DAFF 2017). In the 2015/16 season, maize gross value was approximately equal to R27.5 million (DAFF 2017).

The main maize production regions of South Africa are located in Mpumalanga, Free State and North West provinces, which contributed $21 \%, 39 \%$ and $23 \%$ of the total maize production, respectively, in the 2011/12 season (South African Grain Quality 2011). Mid-summer droughts are commonly experienced in these areas and they normally occur at the end of January (Kgasango 2006). Dry spells and erratic rainfall largely vary from year to year. Such variations are difficult to predict and play a significant role in maize growth and yield (Benhil 2002). Recently, during the 2015/16 growing season, South Africa encountered one of the worst droughts of its history, accompanied by heat waves, which affected greatly the main maize producing regions. Agricultural statistics indicate that maize production was reduced by $24.3 \%$ compared with the previous season 2014/15 (DAFF 2016). Climate projections show that these extreme weather events are likely to increase in the future, which therefore needs us to increase our ability to face adverse conditions.

The objective of the study was to quantify maize yield response to projected climate scenarios in the main maize growing areas of South Africa using two crop modelling solutions (existing and modified CropSyst), which were assessed in a comparative fashion. To achieve the stated objective, the following hypotheses were tested: (i) in the future, average maize grain yields will be lower than previously predicted with models that do not explicitly account for extreme weather events in the main maize growing areas of South Africa, (ii) the average maize grain yields in the near and far future will decrease compared with the baseline climate due to the prevalence of increased extreme droughts and high temperatures besides a general climatic change in the main maize growing areas of South Africa and (iii) food security policy based on modelling solutions taking into account explicitly the impacts of extreme events can better unveil the potential uncertainties associated with future food security.

\section{Materials and methods}

\section{Study sites}

The following three study sites (ESM Fig. 1 in Appendix), with contrasting climates, represent the main maize growing areas in South Africa. Bloemfontein has a dry semi-arid climate with annual rainfall ranging from 400 to $600 \mathrm{~mm}$, Lichtenburg has a sub-humid climate with annual rainfall range of 601 to $800 \mathrm{~mm}$ and Nelspruit has a super humid climate with annual rainfall exceeding $1000 \mathrm{~mm}$. All three study-sites lie in the Highveld region at an altitude range of 900 to $1800 \mathrm{~m}$ above sea level. As in most of Southern Africa, the study sites experience the peak of rainfall in summer, between October and April, with most rainfall falling in December and February. A Hutton soil type (sandy clay loam texture) characterises Nelspruit and Bloemfontein regions, with organic content of 1.4 and $0.7 \%$, respectively (Land Type Survey Staff 2004). 
Lichtenburg region is instead characterised by Avalon soil type (sandy clay loam texture), with organic content of $0.9 \%$ (Land Type Survey Staff 2004).

\section{Description of the climate data}

To simulate potential extreme event impacts on maize, generated climate for the baseline (1991-2020), near future (2021-2050) and the far future (2051-2080) time periods was used. Six GCM (General Circulation Model) simulations from the Coupled Model Intercomparison Project Phase Five (CMIP5) and Assessment Report Five (AR5) of the Intergovernmental Panel on Climate Change (IPCC), obtained for the emission scenarios described by Representative Concentration Pathways (RCPs) 4.5 and 8.5 , were first downscaled to $50-\mathrm{km}$ resolution. Low radiative forcing RCP 4.5 corresponds to a high mitigation scenario, whilst high radiative forcing RCP 8.5 matches a low mitigation scenario. The GCMs that were dynamically downscaled include: the Australian Community Climate and Earth System Simulator (ACCESS1-0), the Geophysical Fluid Dynamics Laboratory Coupled Model (GFDL-CM3), the National Centre for Meteorological Research Coupled Global Climate Model version 5 (CNRM-CM5), the Max Planck Institute Coupled Earth System Model (MPIESM-LR), the Norwegian Earth System Model (NorESM1-M) and the Community Climate System Model (CCSM4) (ESM Table 1 in appendix). These dynamically downscaled simulations were performed on supercomputers of the Centre for High Performance Computing (CHPC) of the Meraka Institute of the CSIR in South Africa. In these simulations, the conformal-cubic atmospheric model (CCAM) was forced with the biascorrected daily sea-surface temperatures (SSTs) and seaice concentrations of each host model, and with $\mathrm{CO}_{2}$, sulphate and ozone forcing consistent with the RCP 4.5 and RCP 8.5 scenarios. The models' ability to realistically simulate present-day Southern African climate has been extensively corroborated (e.g. Engelbrecht et al. 2011; Malherbe et al. 2013; Engelbrecht et al. 2015). Most current coupled GCMs do not employ flux corrections between atmosphere and ocean, which contribute to the existence of biases in their simulations of present-day SSTs - more than $2{ }^{\circ} \mathrm{C}$ along the West African coast. An important feature of the downscaling performed here is that GCMs were forced with bias-corrected sea-surface temperatures (SSTs) and sea-ice fields. The bias was computed by subtracting for each month the Reynolds (1988) SST climatology (for 1991-2000) from the corresponding coupled general circulation model (CGCM) climatology. The bias-correction was applied consistently throughout the simulation. Through this procedure, the climatology of the SSTs applied as lower boundary forcing is the same as that of the Reynolds SSTs. However, the intra-annual variability and climate-change signal of the CGCM SSTs are preserved (Katzfey et al. 2009).

\section{Crop simulations}

Maize grain yields were simulated using a medium season maize (Zea maize L.) hybrid (PAN6966). The simulations were performed for non-limiting soil fertility conditions rainfed maize. Planting dates at Lichtenburg and Bloemfontein were set to day of year (doy) 330 (i.e. just after late-November), whereas for Nelspruit, it was set to day of year 306 (i.e. early November), as practiced by local maize growers. Both the existing (EMS) and the modified (MMS) versions of the crop model CropSyst were calibrated and validated previously for a similar maize hybrid (Mangani et al. 2018). The hypothesis of the general framework for the modified model was developed on the basis that yield variations due to extreme events are generated by changes in HI for water, heat and cold shocks, whereas the main effects of weather on crop performance are already considered by existing crop models (Villalobos et al. 2015). All of these effects are mediated by a change in harvest index (HI). Expressed mathematically, fundamental concepts were implemented into a dedicated module to show how the harvest index is affected by extreme drought and heat events. The comparison of EMS and MMS showed considerable difference between the two model versions during extreme drought and heat events. MMS improved grain-yield prediction by $\sim 30 \%$ compared with EMS, demonstrating a better ability to capture the behaviour of stressed crops under a range of conditions. A detailed description of the changes made to the model can be found in Mangani et al. (2018). The two modelling solutions were run to simulate crop yields for the baseline, near future and far future by changing climate and holding constant all other factors (soil inputs and management strategies (planting date, planting density, fertilisation and crop cultivar)). Each individual GCM was used to run the crop model and afterwards maize yields were averaged across the six GCMs. This was done separately for each location and radiative forcing. This method proved more effective than using an ensemble of GCMs (Rurinda et al. 2015). In as much as ensembles help in improving the modelling of climate data, it may mask the effects of seasonal dry spells. The sensitivity of the maize yield to increased extreme droughts and high temperatures was assessed for the two future climates-2021-2050 (near future) and 2051-2080 (far future) - and was compared with the baseline period (1991-2020). Negative or positive changes of mean yield 
were calculated for each location, RCP, modelling solution and time period. The baseline maize yield was simulated using bias-corrected GCM data output from the three study sites. The effect of atmospheric $\mathrm{CO}_{2}$ level was not investigated as its effect is not well understood on $\mathrm{C} 4$ crops, which are known to be less sensitive to increased levels of atmospheric $\mathrm{CO}_{2}$ (Tubiello et al. 2007; Ainsworth and Ort 2010; Gornall et al. 2010). For the model simulations, a $\mathrm{CO} 2$ concentration level of $396 \mathrm{ppm}$ was used in all simulations.

\section{Results}

\section{Climate projections under different radiative forcing scenarios (RCPs 4.5 and 8.5)}

In all the three study locations, climate projections have shown rainfall seasonality patterns with wet summers (November-March) and dry winters (May-August) (Fig. 1a, c, e and Fig. 2a, c, e). The projections have also shown that the rainfall amount received during the summer period was
Fig. 1 Projected ensemble mean monthly rainfall and temperature for Bloemfontein $(\mathbf{a}, \mathbf{b})$,

Lichtenburg (c, d) and Nelspruit $(\mathbf{e}, \mathbf{f})$ under low radiative forcing for RCP 4.5
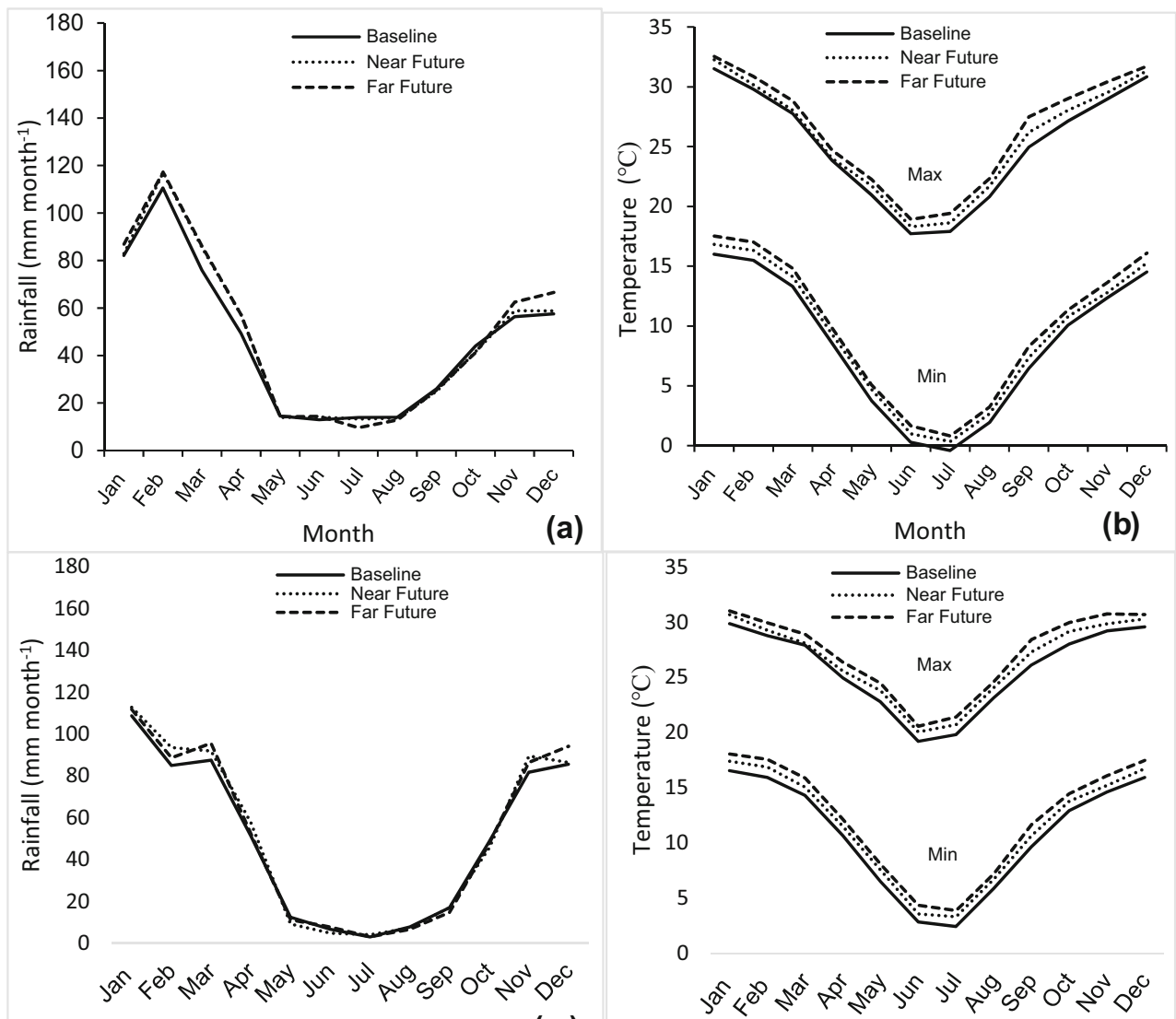

(c)

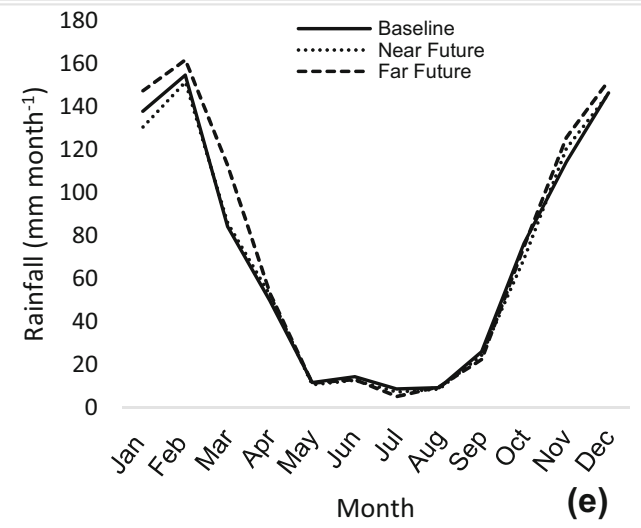

(e)
0

(b)

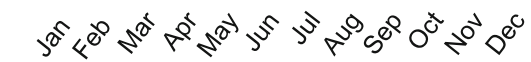

(d)

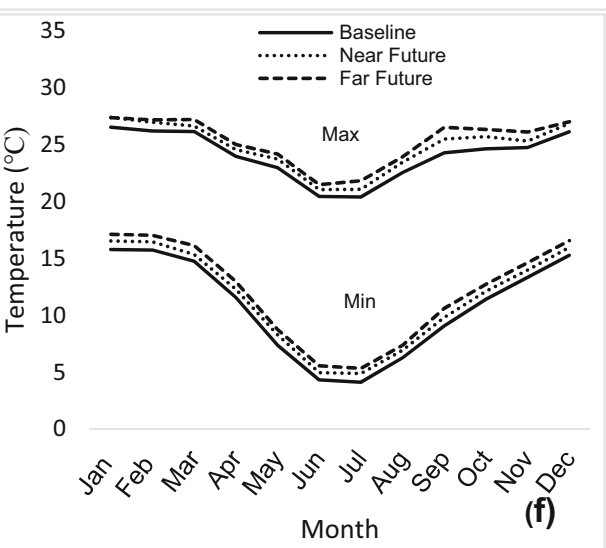


Fig. 2 Projected ensemble mean monthly rainfall and temperature for Bloemfontein $(\mathbf{a}, \mathbf{b})$,

Lichtenburg (c, d) and Nelspruit $(\mathbf{e}, \mathbf{f})$ under high radiative forcing RCP 8.5

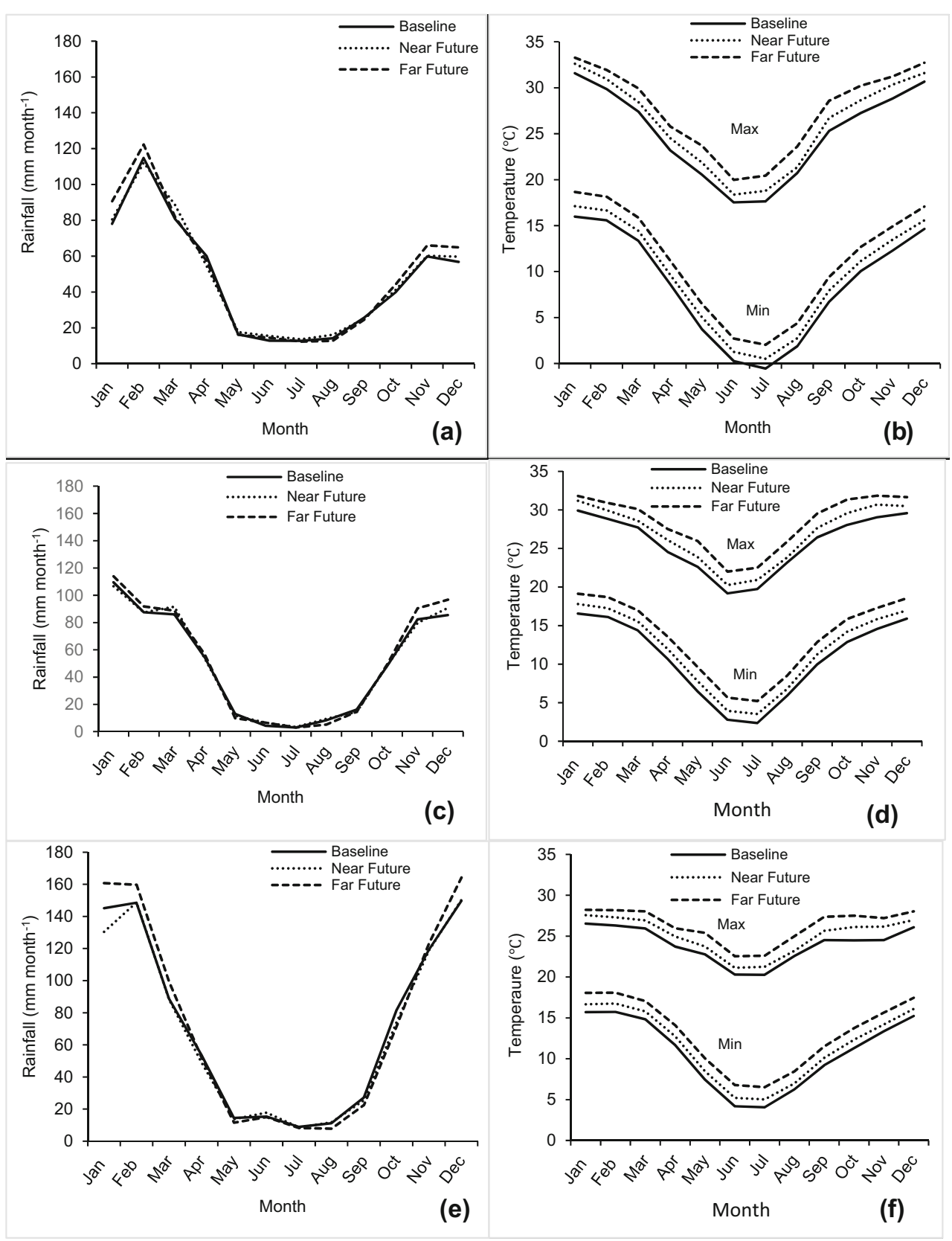

greater in Nelspruit (Fig. 1e) followed by Bloemfontein (Fig. 1a). Generally, the far future projections showed increased rainfall amounts during summer period (cropping season) at Bloemfontein and Lichtenburg compared with the baseline and the near future time horizons. During the winter period, the rainfall amounts of the three time slices seem to be indistinguishable for all the three study sites.

The climate models consistently projected increased temperatures for all the study locations as moving from the baseline to the far future (Fig. 1b, d, f and Fig. 2b, $\mathrm{d}, \mathrm{f})$. This is true for both the average monthly maximum and minimum temperatures of the ensemble models. Differences in monthly temperatures between time horizons are much clearer with the projections from the high radiative forcing (RCP 8.5) (Fig. 2) in comparison with low radiative forcing climate projections (RCP 4.5) (Fig. $2)$. Likewise rainfall, temperature projections show seasonality.

An analysis of extreme temperature events using webXTREME (An R- web-based web tool for calculating agro-climatic indices of extreme events) (http://www. $\underline{\text { modextreme.org/webxtreme) (Klein et al. 2017) shows a }}$ 
positive shift in the median of the number of days with temperature above $30^{\circ} \mathrm{C}$ in a growing season as we move from the baseline to the far future scenario (Fig. 3). This is true for all three study locations.

Additionally, differences in the median values were noted between the climate projections from the two RCPs with the climate data generated by the high radiative forcing (RCP 8.5), having a median value higher than that of the lower radiative forcing (RCP 4.5) at all time periods. With respect to aridity, there was no significant difference between radiative forcing scenarios within a site over time and results for only one radiative forcing was shown in each location (Fig. 4). There was, however, significantly different arid conditions among study sites
(Fig. 4). Bloemfontein appeared to be more arid with a high number of days with ARID $>0.5$ followed by Lichtenburg and Nelspruit, respectively. This was true at all three time horizons.

\section{Projected impacts on maize grain yield}

Simulated crop yield projections using two CropSyst versions (EMS and MMS) varied among time slices and study sites (Fig. 5). Projected mean maize grain yield at all study sites decreased as the time slice progressed from the baseline to the far future climate scenario. This was true for both modelling solutions and climate datasets produced by different RCPs.
Fig. 3 Projected number of days with maximum temperature (Tmax) above $30{ }^{\circ} \mathrm{C}$ for three climate change periods - baseline (1991-2020), near future (2021$2050)$ and far future (20512080) - and two radiative forcing scenarios-RCP 4.5 and RCP 8.5-at (a) Bloemfontein, (b) Lichtenburg and (c) Nelspruit. The box and whisker plots show the variation in the number of days within the growing season based on ensembles of with six global circulation models
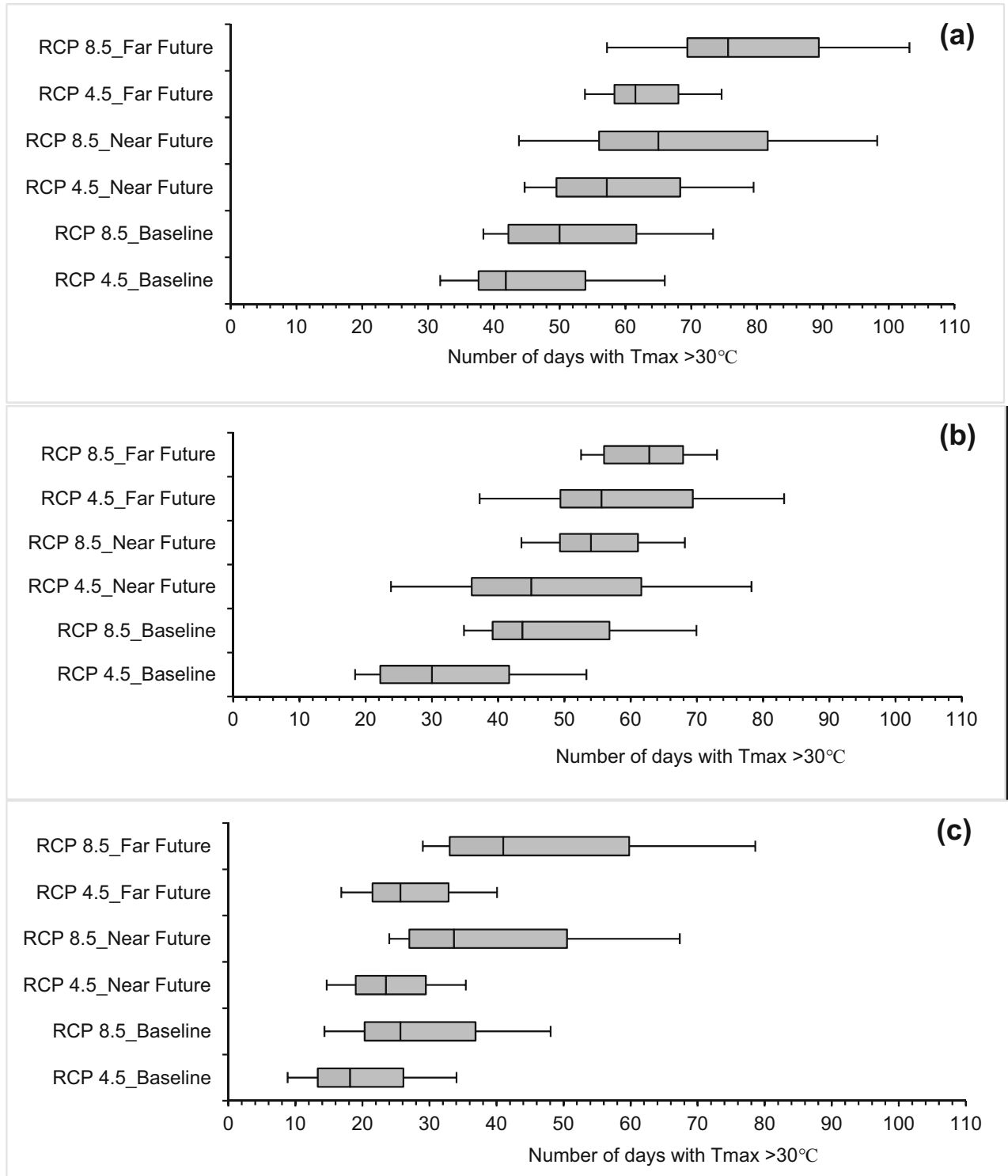
Fig. 4 Projected number of days with ARID $>0.5$ for three climate change periods - baseline (19912020), near future (2021-2050) and far future (2051-2080)- and two radiative forcing scenariosRCP 4.5 and RCP 8.5 - at (a) Bloemfontein, (b) Lichtenburg and (c) Nelspruit

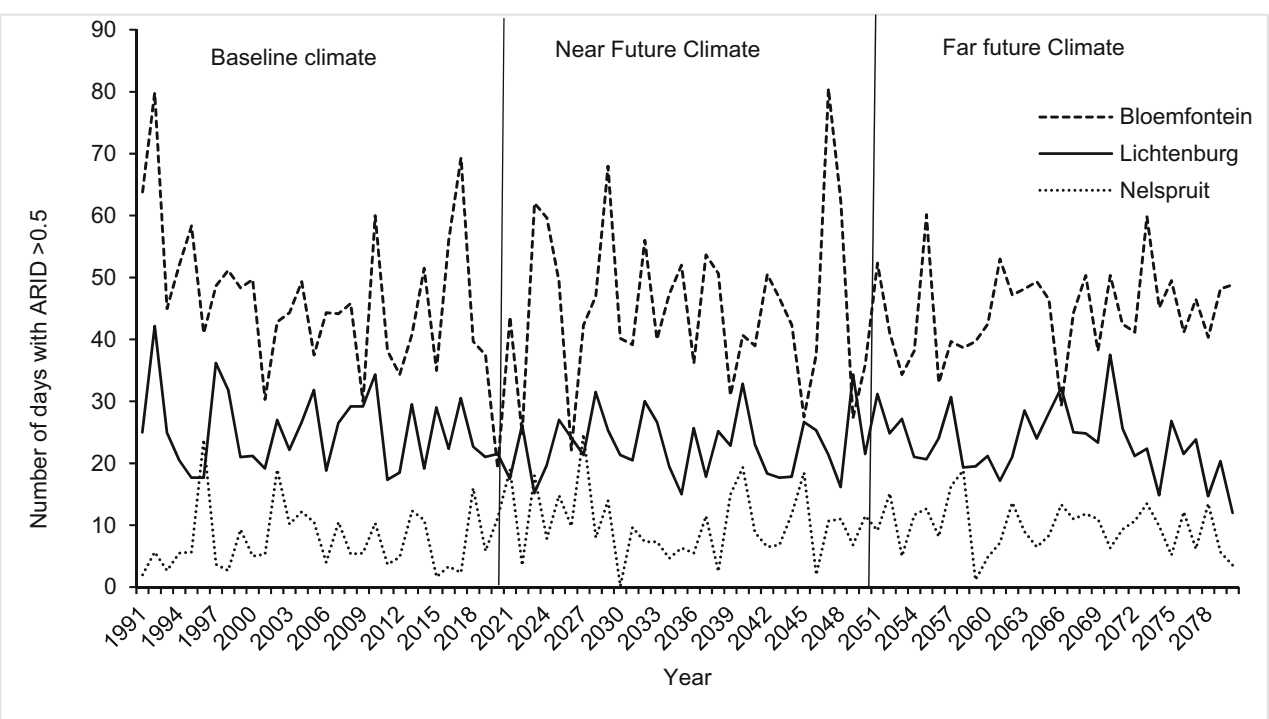

This was also evident in the negative shift in the median of grain yields as we move to the far future climate (Fig. 6).

Generally, maize grain yield simulated by EMS was higher than that simulated by MMS. For instance, the mean EMS simulated maize grain yield obtained using the low radiative forcing (RCP 4.5) for the baseline climate scenario at Bloemfontein, Lichtenburg and Nelspruit was $8.5,8.5$ and $9.8 \mathrm{t} \mathrm{ha}^{-1}$, respectively. While the mean MMS simulated maize grain yield for the same low radiative forcing (RCP 4.5) for the baseline climate scenario was 7.8, 7.4 and $9.0 \mathrm{t} \mathrm{ha}^{-1}$, for Bloemfontein, Lichtenburg and Nelspruit, respectively. Similar trends were observed for simulations ran by high radiative forcing data.

Maize grain yield simulated using low radiative forcing RCP 4.5 climate data was generally higher than high radiative forcing RCP 8.5 at all-time slices and at all locations except for Nelspruit at the baseline period where the grain yield simulated by high radiative forcing data was higher by $0.1 \mathrm{tha}^{-1}$ than that of the lower radiative forcing. The mean (EMS) simulated maize grain yield for Bloemfontein, Lichtenburg and Nelspruit at the far future time slice were 6.7, 7.1 and 8.7 $\mathrm{t} \mathrm{ha}^{-1}$ for RCP 4.5 and 5.8, 6.0 and $8.0 \mathrm{t} \mathrm{ha}^{-1}$ for RCP 8.5 , respectively. A similar trend of higher simulated yields using a lower radiative forcing in comparison with the higher radiative forcing was also observed with MMS simulations.

Overall, the percentage mean grain yield change between baseline and near future, as well as baseline and far future, was the lowest for Nelspruit, which is located in the superhumid agro-ecological zone of South Africa (Table 1). In contrast, the percentage mean grain yield change between base line and far future was highest for Bloemfontein which is located in the semi-arid region. The mean grain yield change between base line and far future in Bloemfontein for the far future time slice decreased by $23 \%$ for RCP 4.5 and $30 \%$ for RCP 8.5 using EMS and by $29 \%$ for RCP 4.5 and $28 \%$ for RCP 8.5 using MMS (Table 1).

The percentage yield deviation between MMS and EMS was the lowest for Nelspruit and the highest for Bloemfontein (Table 2). The percentage yield deviation of MMS from EMS increased as the time slice progressed from baseline to far future at all study sites for both RCPs. In each study site, the deviation between MMS and EMS was higher for RCP 8.5 compared with RCP 4.5 at similar time slices.

Projections indicate a reduced number of days to reach maturity as with the far future climate in all study sites (Fig. 7). No significant differences were noted on the projected number of days to reach maturity with different crop modelling solutions. Yield response variations across all locations and radiative forcing scenarios ranged between a mean coefficient of variation (CV) of 6.9 and 39\% (ESM Fig. 2 in Appendix). Similar trends were observed across all locations with significantly higher mean CVs obtained with MMS than EMS simulations.

\section{Discussion}

\section{Crop yield changes}

There has been a gradual decline in simulated maize yields as time slice progresses from the baseline time period to the far future at all three study sites, irrespective of the crop modelling solution used. Such a trend shows the manifestation of climate change effects on crop yields. Yield declines are mainly attributed to the increased temperatures projected in future climate scenarios. Greater yield losses were realised in the much 
Fig. 5 Simulated mean maize yield obtained using existing modelling solution (EMS) and modified modelling solution (MMS) at different time horizons, two radiative forcing scenarios (RCP 4.5 and RCP 8.5) at three sites: A) Bloemfontein, B) Lichtenburg and C) Nelspruit. Capped lines are \pm standard error
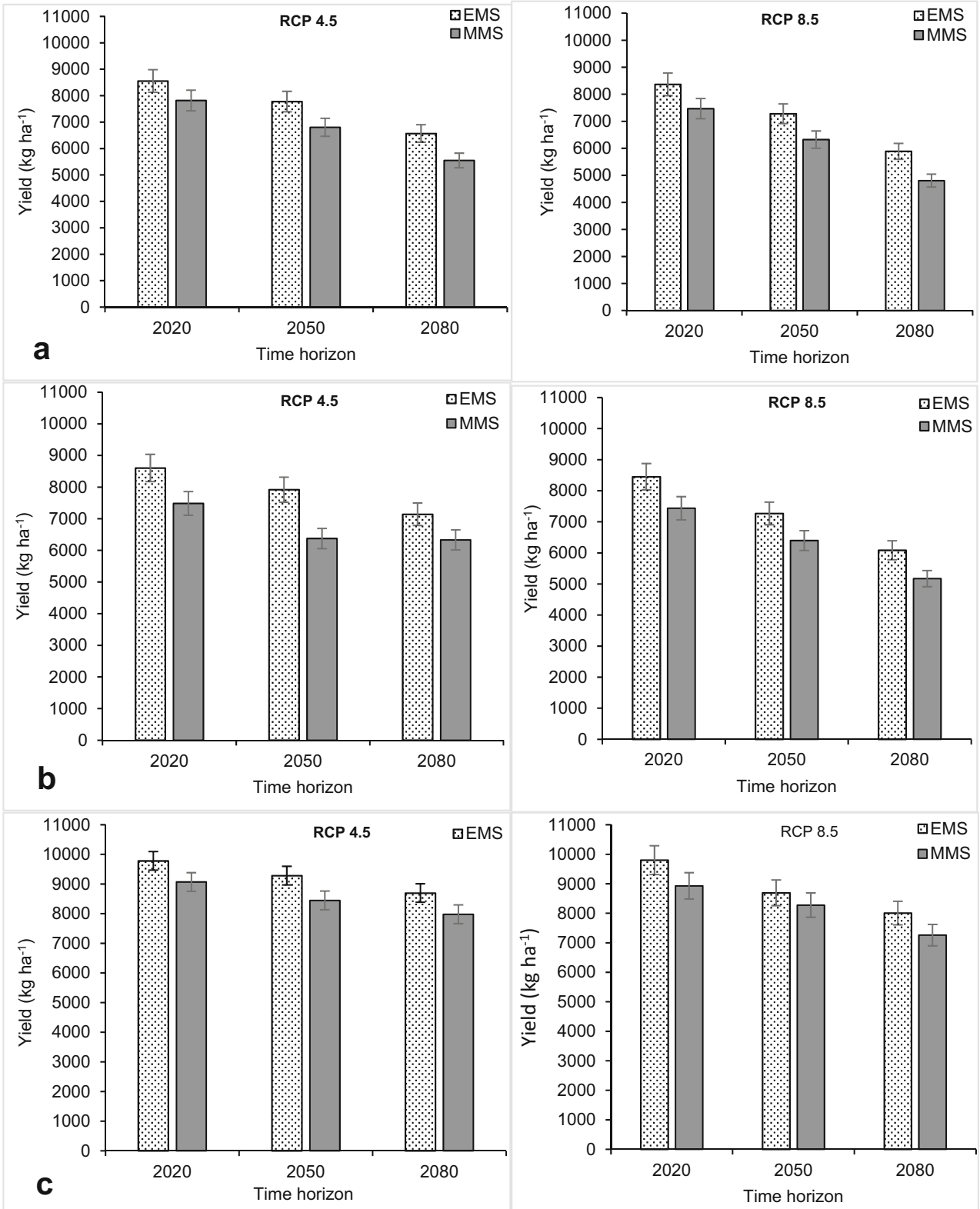

warmer locations (Bloemfontein and Lichtenburg) compared with a cooler area (Nelspruit). Increased temperatures triggered anticipated maturity dates, that is, reduced growing seasons for maize (Springate and Kover 2014). A shorter growing period implies less time available to accumulate crop biomass, which consequently translates into yield reductions (Haverkort et al. 2013). Yields also decreased more with the use of high radiative forcing climate data in comparison with low radiative forcing data. Indeed, projections from the high radiative forcing generate increased temperatures compared with the low radiative forcing. Similar findings of greater declines in yield using high radiative forcing in comparison with the yields simulated using climate data from low radiative forcing have been reported by Rurinda et al. (2015).

A few studies related to climate change impact on maize have been carried out in the same regions covered by the current study. Previous studies used modelling solutions (comparable with our EMS) that do not take into account explicitly the impacts of extreme weather events (Jones and Thornton 2003; Walker and Schulze 2006; Parry et al. 2004; Lobell 2010; Rurinda et al. 2015). For instance, Jones and Thornton (2003) projected yield reductions of approximately $20 \%$ for South Africa in 2055. These simulated results were obtained with the crop model CERES-Maize and climate data generated from one GCM, not from an ensemble of GCMs as in our study. A number of uncertainties have been cited 
Fig. 6 Box plots comparing the grain yield of simulated rain fed maize yields under different time horizons using the existing (EMS) and modified (MMS) CropSyst modelling solutions for different time horizons at three sites: (a) Bloemfontein, (b) Lichtenburg and (c) Nelspruit. Vertical lines in shaded boxes are the median; whiskers represent the upper and lower quartiles
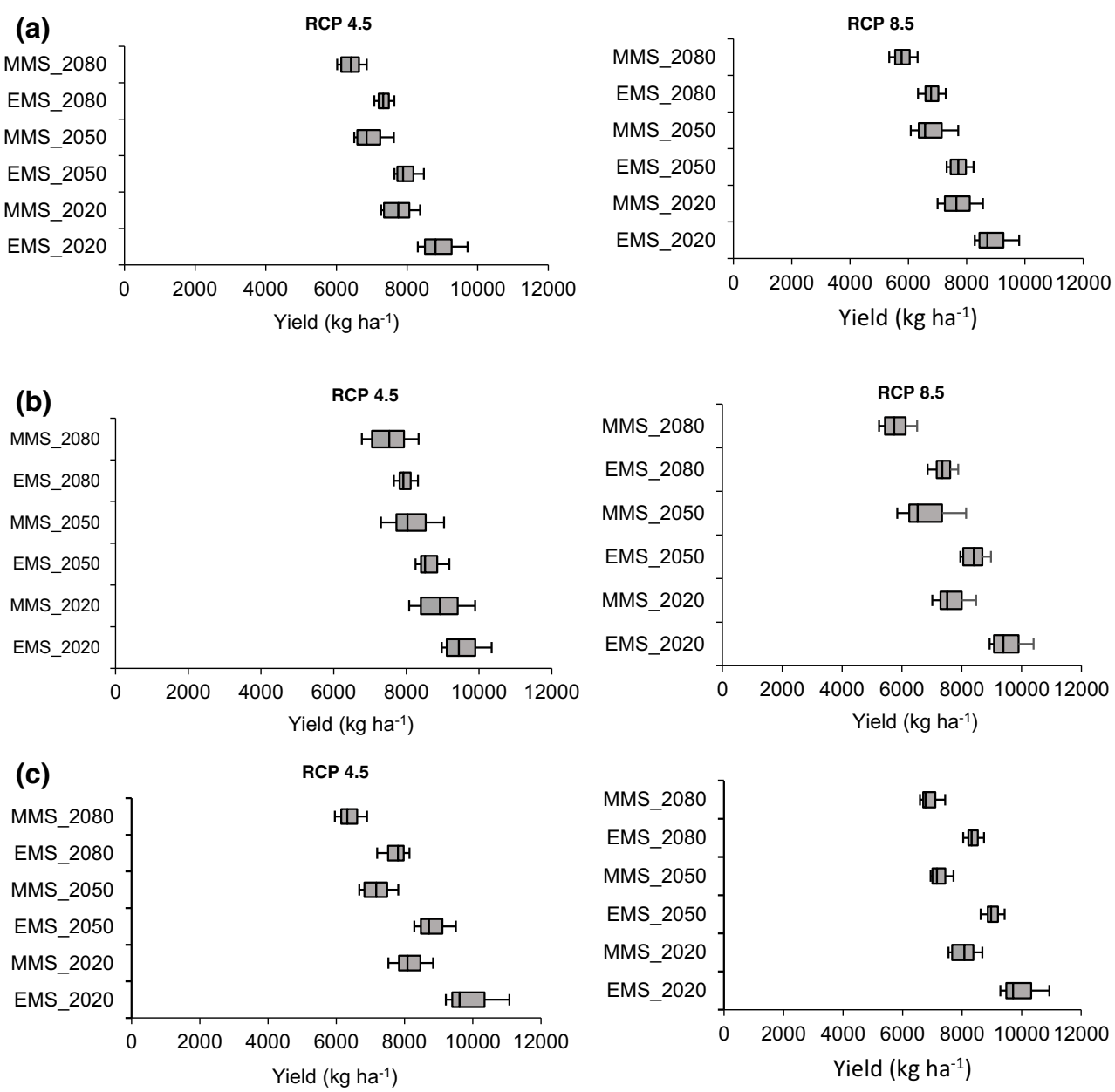

previously from using one GCM, which might have led to over predictions $(\sim 20 \%)$ of yield decline in comparison with our results (maximum of 13\%) during the same period. Parry et al. (2004) projected yield declines of $10 \%$ and $30 \%$ during the 2050s and 2080s, respectively, using the A1FI climate scenario which is the warmest of the Special Report on Emissions Scenarios (SRES) of the Intergovernmental Panel on Climate Change (IPCC, 2007). Although these values were representing the larger part of Africa where maize is grown, they were within the range of results we obtained using an existing CropSyst model. In another study conducted in a nearby country, Zimbabwe, in which the agricultural production systems simulator (APSIM) model was used, maize yield was estimated to decline by $\sim 32 \%$ for the period 2070-2099 under the high radiative forcing and by $20 \%$ using the low radiative forcing (Rurinda et al. 2015). The climate data scenarios used in these studies agree well with ours, and these findings fall within our range of values.

Our analysis suggests that the mean maize grain yield in the main maize producing areas of South Africa will likely decrease as a result of the projected increase in the number of days with extreme temperatures $\left(>30^{\circ} \mathrm{C}\right)$, as illustrated by the modified modelling solution (MMS). With no trends of increasing aridity in the three study areas, temperature is the main cause for the projected future yield losses. The modified CropSyst version used in the study shows some decreasing trends in future maize yields, which is consistent with the projected increase in the number of days with temperatures above $30{ }^{\circ} \mathrm{C}$. While similar trends of decreasing yields have been observed in all the studied locations, the potential impacts of extreme weather events are expected to be more pronounced in the Bloemfontein area. In this area, differences between EMS and MMS in the projected maize grain yield were on average of $20 \%$ and $15 \%$ at the far future time horizon using the high and low radiative forcing, respectively (Table 2). In Nelspruit, which is less arid and less affected by extreme temperatures compared with the other two study sites, differences in yield between the two modelling solutions at the far future time horizon were $\sim 12 \%$ and $\sim 9 \%$ with high and low radiative forcing, respectively. Such differences indicate the ability of MMS to capture the impacts on yield of extreme drought and heat events. This suggests that using models not taking explicitly into account the impact of extreme weather events can be misleading and may have some repercussions on the country's food security preparedness. 
Table 1 Percentage mean grain yield changes between baseline and future (far and near) periods for two modelling solutions: existing modelling solution (EMS) and modified modelling solution (MMS), two radiative forcing scenarios (RCP 4.5 and RCP 8.5) at three sites: (A) Bloemfontein, (B) Lichtenburg and (C) Nelspruit

\begin{tabular}{lllcc}
\hline \multirow{2}{*}{ Location } & & \multicolumn{2}{c}{ Grain yield deviation from baseline (\%) } \\
\cline { 3 - 5 } & Time scenario & RCP & EMS & MMS \\
\hline \multirow{2}{*}{ Bloemfontein } & Near future (2021-2050) & 4.5 & -9.1 & -13.01 \\
& Far future (2051-2080) & 4.5 & -23.19 & -29.00 \\
& Near future (2021-2050) & 8.5 & -13.8 & -15.32 \\
& Far future (2051-2080) & 8.5 & -29.6 & -27.65 \\
\multirow{3}{*}{ Lichtenburg } & Near future (2021-2050) & 4.5 & -13.76 & -14.81 \\
& Far future (2051-2080) & 4.5 & -21.6 & -15.4 \\
& Near future (2021-2050) & 8.5 & -14.01 & -14.00 \\
& Far future (2051-2080) & 8.5 & -25.99 & -6.8 \\
\multirow{3}{*}{ Nelspruit } & Near future (2021-2050) & 4.5 & -5.1 & -12.00 \\
& Far future (2051-2080) & 4.5 & -11.1 & -7.3 \\
& Near future (2021-2050) & 8.5 & -11.3 & -18.72 \\
& Far future (2051-2080) & 8.5 & -18.3 & \\
& & & &
\end{tabular}

According to DAFF (2015), in 2014/15 the area under maize (both white and yellow) production in Free State Province of South Africa was 1,220,000 ha. If simulations are performed using the two modelling solutions and it is assumed that (i) the weather and basic soil properties are the same across Free State Province and (ii) the agricultural management practices also remain the same and (iii) also assume that the average yield per hectare will be $8 \mathrm{t}$. This implies that if we make use of the upper limit of the differences obtained in the study from the two modelling solutions for Bloemfontein (which is $20 \%$ ), the projected production levels will be 9,760,000 and 7,808,000 tons with EMS and MMS, respectively. The difference in maize production levels per given area under production between the two modelling solutions would be $\sim 2$ million tons. Failing in production estimation by approximately $20 \%$ can have fatal implications on food security planning and policy formulation. This illustrates the negative implications that can be brought about on current and

Table 2 Percentage yield deviation of MMS from EMS at different time periods and three study sites, for two radiative forcing scenarios (RCP 4.5 and 8.5)

\begin{tabular}{lllll}
\hline RCP & Time horizon & Bloemfontein & Lichtenburg & Nelspruit \\
\hline 4.5 & Baseline & 8.61 & 12.01 & 6.9 \\
& Near future & 12.54 & 13.01 & 7.79 \\
& Far future & 16.27 & 15.03 & 9.37 \\
8.5 & Baseline & 10.75 & 13 & 7.3 \\
& Near future & 13.14 & 14.06 & 9.01 \\
& Far future & 20.41 & 18.06 & 12.23 \\
\hline
\end{tabular}

future food security projections and policy, depending on the modelling solution used.

From the simulations carried out, results indicate that Bloemfontein followed by Lichtenburg will be mostly affected by extreme temperature events associated with temperature increase. It is recommended that researchers look into options that can help to reduce the risk that extreme weather events might have on maize production in the future. These areas lie in the largest producing areas of maize in South Africa and this calls for urgency in finding ways to adapt. New maize genotypes with improved drought and heat tolerance will play an important role in adapting maize-based systems to climate change and extreme weather events in South Africa and the Sub-Saharan African region.

\section{Uncertainties and limitations of the study}

The limitations to this study include the fact that farmers respond to changes in climate, and any adaptive measures that can be implemented by farmers would result in a different response of crops, e.g. in the case that maize hybrids that can resist high temperature will be used of in the future. Secondly, the modified CropSyst model used in this study did not consider the impacts of flooding, which can also have some other negative effects on crop production. Similarly, the model does not consider the negative impacts of pests, diseases and weeds on grain yield hence the values obtained must be treated with caution as they may underestimate the impact of extreme weather events on maize. Lastly, one hybrid was used in this study as was the case for model calibration by Mangani et al. (2018). Extrapolation of these results to other study 
Fig. 7 Box plots comparing the maturity dates of simulated rain fed maize yields under different climate scenarios with using the existing (EMS) and modified (MMS) CropSyst modelling solutions for different time horizon at three sites: (a) Bloemfontein, (b) Lichtenburg and (c) Nelspruit. Vertical lines in shaded boxes are the median; whiskers represent the upper and lower quartiles

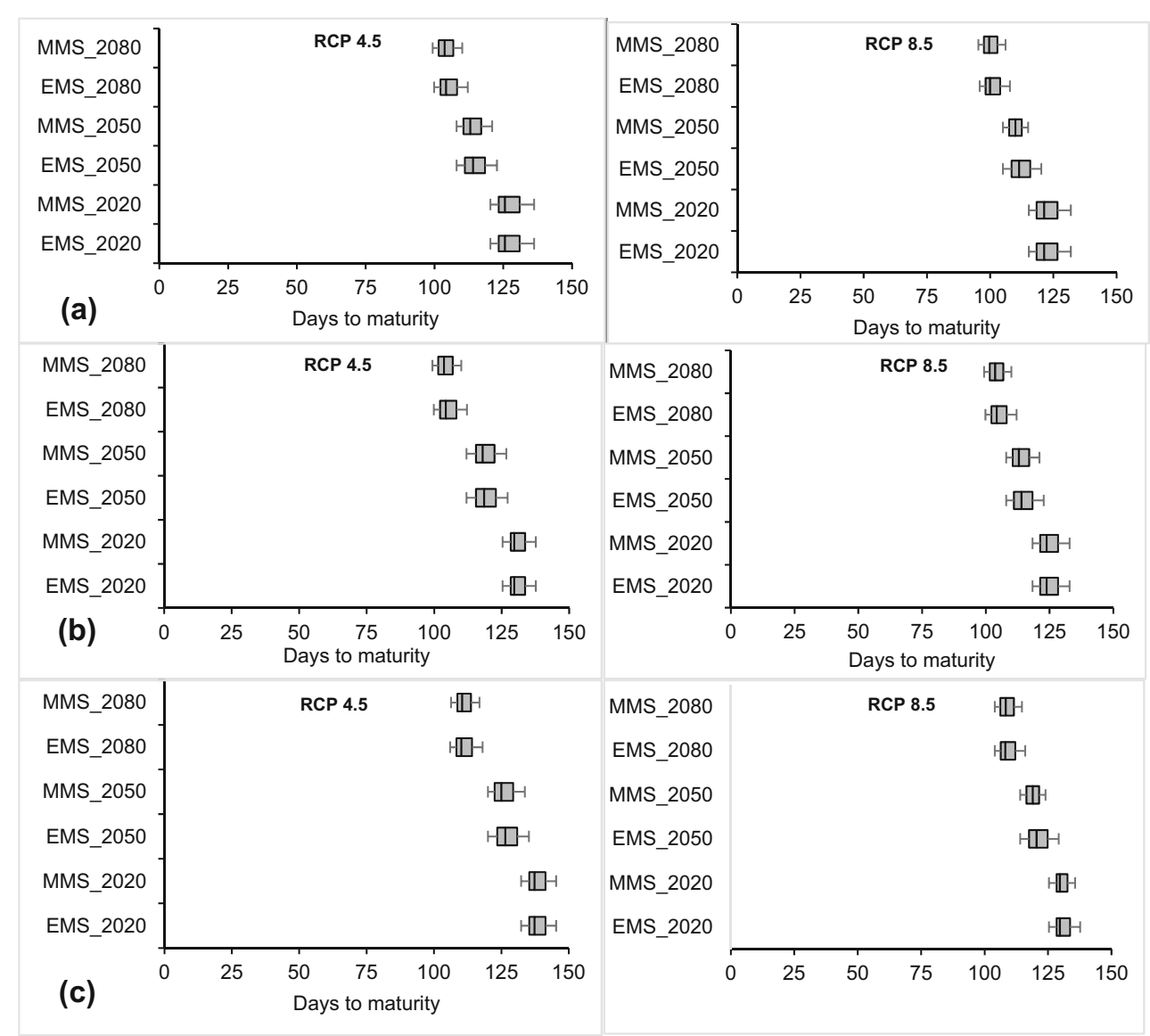

sites should be made with caution as using different hybrids might lead to different results.

\section{Conclusions and recommendations}

Models that do not take into account the impact of extreme weather events might underestimate the potential impact of future climate on maize production in South Africa, resulting in higher yield projections. This has adverse effects on food security planning and policy formulation. As we have observed in the studied locations that yields can be overestimated by $20 \%$, which, converted to tons, can be a sizeable figure that can emanate food insecurity. Location-specific studies are crucial, as the incidence and frequency of extreme events in future climate might be different from one to the other. This calls for different adaptive options for different locations to face extreme climate. The results of this study show that Bloemfontein needs policies that can make maize growers able to face future extreme weather events before yields drop drastically. Future research should focus on using ensembles of crop models with algorithms that take into account the impact of extreme weather events. This would reduce the uncertainties brought about by using one crop model only.
Funding information The research leading to these results has received funding from the European Community's Seventh Framework Programme (FP7/2007-2013) under grant agreement no. 613817 (MODEXTREME - Modelling vegetation response to EXTREMe Events, http://modextreme.org).

\section{References}

Abraha MG, Savage MJ (2006) Potential impacts of climate change on the grain yield of maize for the midlands of KwaZulu-Natal, South Africa. Agric Ecosyst Environ 115(1):150-160. https://doi.org/10. 1016/j.agee.2005.12.020

Ainsworth EA, Ort DR (2010) How do we improve crop production in a warming world? Plant Physiol 154(2):526-530. https://doi.org/10. 1104/pp.110.161349

Akpalu W, Hassan RM, Ringler C (2009) Climate variability and maize yield in South Africa Intl food policy res Inst. IFPRI paper, 843

Benhil J (2002) Climate, Water and Agriculture: Impacts on and Adapatation of Agro Ecological Systems in South Africa. University of Pretoria, South Africa

Bentsen M, Bethke I, Debernard JB, Iversen T, Kirkevla ag A, Seland Ø, Drange H, Roelandt C, Seierstad IA, Hoose C (2013) The Norwegian earth system model, NorESM1-M-part 1: description and basic evaluation of the physical climate. Geosci Model Dev 6(3):687-720. https://doi.org/10.5194/gmd-6-687-2013

Delworth TL, Broccoli AJ, Rosati A, Stouffer RJ, Balaji V, Beesley JA, Cooke WF, Dixon KW, Dunne J, Dunne KA (2006) GFDL's CM2 global coupled climate models. Part I: formulation and simulation 
characteristics. J Clim 19(5):643-674. https://doi.org/10.1175/ JCLI3629.1

Department of Agriculture, Forestry and Fisheries (DAFF) (2016) A profile of the South African maize market value chain. Department of Agriculture, Forestry and Fisheries, Pretoria, South Africa. Retrieved from https://www.nda.agric.za/doaDev/sideMenu/ Marketing/Annual\%20Publications/Commodity\%20Profiles/ field $\% 20 \mathrm{crops} /$ Maize $\% 20$ Market $\% 20$ value $\% 20$ Chain $\% 20$ Profile $\%$ 202016.pdf. Accessed 16 May 2018

Department of Agriculture, Forestry and Fisheries (DAFF) 2017 Trends in the agriculture sector 2017. Department of Agriculture, Forestry and Fisheries, Pretoria, South Africa. Retrieved from https://www. daff.gov.za/Daffweb3/Portals/0/Statistics\%20and\%20Economic\% 20Analysis/Statistical\%20Information/Trends\%20in\%20the\% 20Agricultural\%20Sector\%202016.pdf. Accessed 4 February 2018

Dix M, Vohralik P, Bi D, Rashid H, Marsland S, O'Farrell S, Uotila P, Hirst T, Kowalczyk E, Sullivan A (2013) The ACCESS coupled model: documentation of Core CMIP5 simulations and initial results. Aust Meteorol Oceanogr J 63(1):83-99

Engelbrecht FA, Landman WA, Engelbrecht CJ, Landman S, Bopape MM, Roux B, McGregor JL, Thatcher M (2011) Multi-scale climate modelling over Southern Africa using a variable-resolution global model. Water SA 37(5):647-658

Engelbrecht FA, Adegoke J, Bopape M, Naidoo M, Garland R, Thatcher M, McGregor J, Katzfey J, Werner M, Ichoku C (2015) Projections of rapidly rising surface temperatures over Africa under low mitigation. Environ Res Lett 10(8):085004. https://doi.org/10.1088/17489326/10/8/085004

Estes LD, Beukes H, Bradley BA, Debats SR, Oppenheimer M, Ruane AC, Schulze R, Tadross M (2013) Projected climate impacts to South African maize and wheat production in 2055: a comparison of empirical and mechanistic modeling approaches. Glob Chang Biol 19(12):3762-3774. https://doi.org/10.1111/gcb.12325

FAO (2012) FAOStat: production. http://faostat.fao.org

Gent PR, Danabasoglu G, Donner LJ, Holland MM, Hunke EC, Jayne SR, Lawrence DM, Neale RB, Rasch PJ, Vertenstein M (2011) The community climate system model version 4. J Clim 24(19):49734991. https://doi.org/10.1175/2011JCLI4083.1

Gornall J, Betts R, Burke E, Clark R, Camp J, Willett K, Wiltshire A (2010) Implications of climate change for agricultural productivity in the early twenty-first century. Philos Trans R Soc B: Biol Sci 365(1554):2973-2989. https://doi.org/10.1098/rstb.2010.0158

Haverkort AJ, Franke AC, Engelbrecht FA, Steyn JM (2013) Climate change and potato production in contrasting South African agroecosystems 1. Effects on land and water use efficiencies. Potato Res 56(1):31-50. https://doi.org/10.1007/s11540-013-9230-4

Jones PG, Thornton PK (2003) The potential impacts of climate change on maize production in Africa and Latin America in 2055. Glob Environ Chang 13(1):51-59. https://doi.org/10.1016/S09593780(02)00090-0

Jungclaus JH, Keenlyside N, Botzet M, Haak H, Luo JJ, Latif M, Marotzke J, Mikolajewicz U, Roeckner E (2006) Ocean circulation and tropical variability in the coupled model ECHAM5/MPI-OM. J Clim 19(16):3952-3972. https://doi.org/10.1016/S0959-3780(02) 00090-0

Katzfey JJ, McGregor JL, Nguyen KC, Thatcher M (2009) Dynamical downscaling techniques: impacts on regional climate change signals. In World IMACS/MODSIM Congress, Cairns, 2377-2383

Kgasango H (2006) Effect of planting dates and densities on yield components of short and ultra-short growth period maize (Zea Mays L.). University of Pretoria

Klein T, Samourkasidis A, Athanasiadis IN, Bellocchi G, Calanca P (2017) webXTREME: R-based web tool for calculating agroclimatic indices of extreme events. Computers and electronics in agriculture 15(136):111-116. https://doi.org/10.1016/j.compag. 2017.03.002

Land Type Survey Staff (2004) Land types of South Africa on 1:250 000 scale. In Memoirs of the Agricultural Natural Resource of South Africa, Vol. 1-13. Pretoria: Agricultural Research Council: Institute for Soil, Climate and Water. n.d.

Malherbe J, Engelbrecht FA, Landman WA (2013) Projected changes in tropical cyclone climatology and landfall in the Southwest Indian Ocean region under enhanced anthropogenic forcing. Clim Dyn 40(11-12):2867-2886. https://doi.org/10.1007/s00382-012-1635-2

Mangani R, Tesfamariam E, Bellocchi G, Hassen A (2018) Modelled impacts of extreme heat and drought on maize yield in South Africa. Crop Pasture Sci 69(7):703-716. https://doi.org/10.1071/ CP18117

Parry ML, Rosenzweig C, Iglesias A, Livermore M, Fischer F (2004) Effects of climate change on global food production under SRES emissions and socio-economic scenarios. Glob Environ Chang 14(1):53-67. https://doi.org/10.1016/j.gloenvcha.2003.10.008

Reynolds RW (1988) A real-time Global Sea surface temperature analysis. J Clim 1(1):75-87. https://doi.org/10.1175/1520-0442(1988) 001<0075:ARTGSS>2.0.CO;2

Rurinda J, Wijk MT, Mapfumo P, Descheemaeker K, Supit I, Giller KE (2015) Climate change and maize yield in Southern Africa: what can farm management do? Glob Chang Biol 21(12):4588-4601. https:// doi.org/10.1111/gcb.13061

Salas-Mélia D, Chauvin F, Déqué M, Douville H, Gueremy JF, Marquet P, Planton S, Royer JF, Tyteca S (2005) Description and validation of the CNRM-CM3 global coupled model. CNRM Working Note 103:36

South African Grain Quality (2011) South African Maize-Crop Quality Report 2010/2011 Season, 2011

Springate DA, Kover PX (2014) Plant responses to elevated temperatures: a field study on phenological sensitivity and fitness responses to simulated climate warming. Glob Chang Biol 20(2):456-465. https://doi.org/10.1111/gcb.12430

Stöckle CO, Martin MA, Campbell GS (1994) CropSyst, a cropping systems simulation model: water/nitrogen budgets and crop yield. Agric Syst 46:335-359. https://doi.org/10.1016/0308-521X(94) 90006-2

Stöckle CO, Cabelguenne M, Debaeke P (1997) Comparison of CropSyst performance for water management in southwestern France using sub models of different levels of complexity. Eur J Agron 7:89-98. https://doi.org/10.1016/S1161-0301(97)00033-6

Tubiello FN, Soussana JF, Howden SM (2007) Crop and pasture response to climate change. Proc Natl Acad Sci 104(50):19686-19690

van der Velde M, Tubiello FN, Vrieling A, Bouraoui F (2012) Impacts of extreme weather on wheat and maize in France: evaluating regional crop simulations against observed data. Clim Chang 113(3-4):751765. https://doi.org/10.1007/s10584-011-0368-2

Walker NJ, Schulze RE (2006) An assessment of sustainable maize production under different management and climate scenarios for smallholder agro-ecosystems in KwaZulu-Natal, South Africa. Phys Chem Earth, Parts A/B/C 31(15):995-1002. https://doi.org/ 10.1016/j.pce.2006.08.012

Walker NJ, Schulze RE (2008) Climate change impacts on agroecosystem sustainability across three climate regions in the Maize Belt of South Africa. Agric Ecosyst Environ 124(1):114-124. https://doi.org/10.1016/j.agee.2007.09.001

Zinyengere N, Crespo O, Hachigonta S, Tadross M (2014) Local impacts of climate change and agronomic practices on dry land crops in Southern Africa. Agric Ecosyst Environ 197:1-10. https://doi.org/ 10.1016/j.agee.2014.07.002

Publisher's note Springer Nature remains neutral with regard to jurisdictional claims in published maps and institutional affiliations. 